\title{
Chapter
}

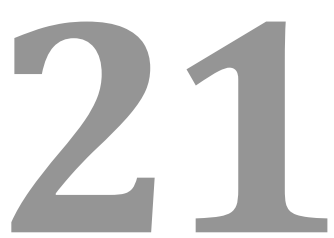

\section{LIVER TISSUE ENGINEERING}

\section{Florin Graur ${ }^{1,2 *}$}

${ }^{1}$ University of Medicine and Pharmacy "Iuliu Hatieganu" Cluj-Napoca, Romania

${ }^{2}$ Regional Institute of Gastroenterology and Hepatology "O. Fodor" Cluj-Napoca, Romania 


\section{Contents}

21.1. INTRODUCTION 553

21.2. METHODS TO OBTAIN A CELL POPULATION SUITABLE FOR RECELLULARISING THE MATRIX

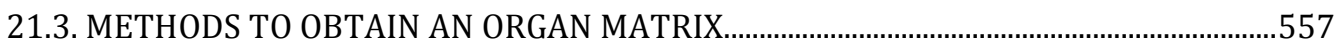

21.4. METHODS FOR RECELLULARISING THE SCAFFOLDS.....................................................559

21.5. APPLICATIONS OF RECONSTRUCTED ORGANS ................................................................56

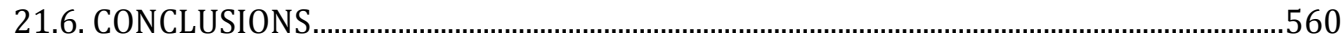

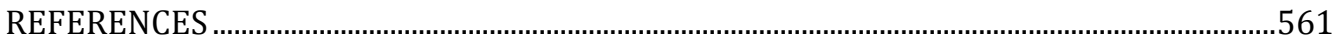




\subsection{INTRODUCTION}

The only solution for chronic, final-stage liver diseases and acute liver failure is liver transplantation, which is long-term and radical. The causes of these diseases are genetic, toxic, congenital, parasitic, iatrogenic, etc. However, the demand far exceeds the number of donors for liver transplantation, as can be seen by analysing waiting lists. In addition, there are religious limitations in some situations that reduce the options in the case of deceased donors.

Various ways to save organs available for donation have been sought: splitliver, domino transplant, living-related transplant, marginal transplant, etc. In addition to the lack of organs, there are complications in the post-transplant period that can compromise the graft and are primarily due to the body's immune reaction or immunosuppressive treatment administered to limit the immune response of the body against the graft.

Long waiting lists for organ transplants (liver, kidney, heart and lung) and reduced availability of organs from donors has led to further research in order to obtain organs from other sources.

There were initial hopes regarding transplants from animals to humans (xenotransplantation), but most recent research has focused on obtaining artificial organs.

A number of solutions have been developed utilising extracorporeal liver filtration membranes or absorption systems to remove toxins from the blood. Of these, the most common are molecular adsorbents recirculating system (MARS), liver dialysis devices and Prometheus. BioArtificial Liver (BAL) systems are also extracorporeal systems that perform detoxification, metabolic and synthesis functions. These systems are composed of primary hepatocyte or hepatoma cell lines and membranes that separate functional hepatocytes from the patient's plasma. The best known are HepatAssist and extracorporeal liver assist device (ELAD).

To obtain quality synthetic organs, it is necessary to have a scaffold structure compatible with the host organism and the cells to repopulate it. Stem cells have a promising potential in terms of developing in vitro organs due to the proliferative activity and the potential of differentiation into almost any type of mature cell (Figure 1). Stem cells have shown that they have the ability to differentiate into mature liver cells [1-3]. 


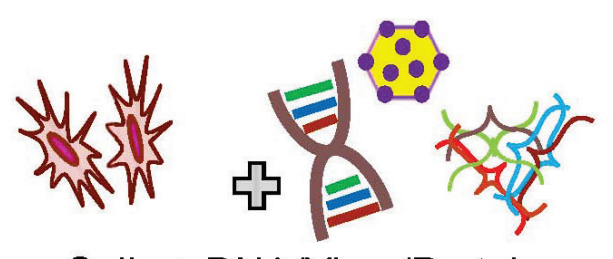

Cells + DNA/Virus/Protein

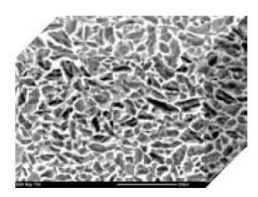

Cell Seeded in porous scaffolds
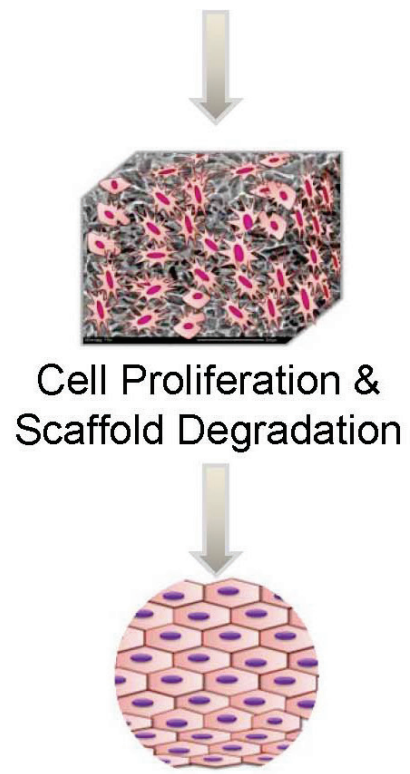

Engineered Tissue

Figure 1. Classic approach to tissue engineering (from Tiruvannamalai-Annamalai et al. 2014) [4]

There are also new developments in tissue engineering such as the modular approach (Figure 2). 

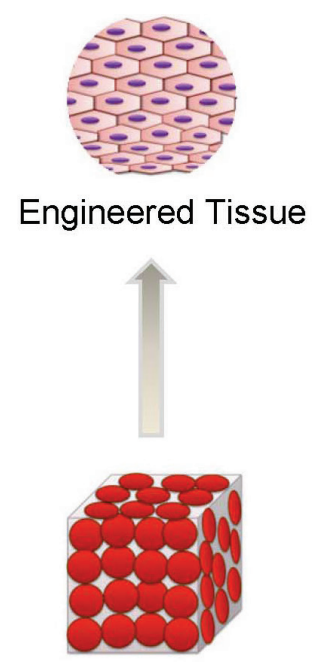

Module Assembly

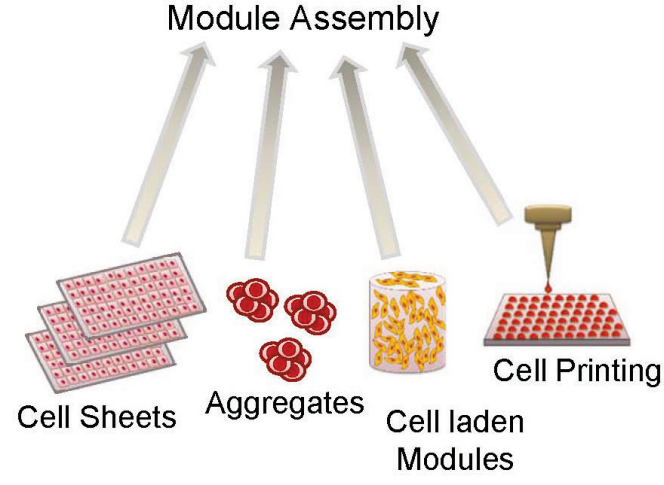

Figure 2. Modular tissue engineering (from Tiruvannamalai-Annamalai et al. 2014) [4]

Current problems researchers are facing are a lack of a compatible and functional scaffold structures for in vitro liver development, a lack of selected stem cells, and immunological barriers, which also constitute an impediment for the construction of synthetic organs.

However, research conducted so far in this area constitutes an important step in obtaining synthetic organs.

Essential characteristics of engineered liver tissue are to perform the essential functions of the liver: plasma protein synthesis; ketogenesis; synthesis of urea; detoxification; and immune function.

The liver is composed mostly of hepatocytes (approx. $70 \%$ of the cell population), Kuppfer cells, progenitor cells (Ito cells), stellate cells, biliary epithelial cells, sinusoidal epithelial cells and fibroblasts [5]. 


\subsection{METHODS TO OBTAIN A CELL POPULATION SUITABLE FOR RECELLULARISING THE MATRIX}

The source of the cells is particularly important because they must have the potential to differentiate into mature hepatocytes. Different cell types have been tested for liver fibrous scaffold repopulation: hematopoietic cells, stem cells, Ito cells and hepatocyte mature cells [6-8].

Initial experiments were performed with mature liver cells. Mature hepatocytes in laboratory conditions did not sufficiently multiply, nor did they retain their differentiation characteristics [9].

Subsequently, researchers sought other sources for cells to repopulate matrices, testing hematopoietic stem cells from bone marrow, known for their superior plasticity to differentiate into various types of mature cells. Adult stem cells from bone marrow mesenchymal stem cells (BMSCs) can easily be harvested via bone marrow puncture, multiplied in vitro, and oriented towards subsequent differentiation into mature hepatocytes for liver scaffold repopulation. Adult stem cells are preferred to embryonic stem cells because there are a series of limitations relating to the use of the latter in therapy in humans, including ethical issues.

A number of inductive environmental factors dictate the stem cell differentiation. The cells in the immediate vicinity or scaffold characteristics can also guide the subsequent differentiation that the cell will follow.

Paracrine factors influencing hepatocyte differentiation and cell growth are hepatocyte growth factor (HGF), fibroblastic growth factor (FGF), activin, bone morphogenesis protein (BMP), oncostatin M (OSM), epidermal growth factor (EGF), interleukin-6 (IL-6), transforming growth factor alpha (TGF- $\alpha$ ), and insulin growth factor (IGF). There are also drugs that affect hepatocyte differentiation: dimethyl sulfoxide (DMSO), steroids, amino acids, and nicotinamide. Intracellular regulators of gene expression involved in hepatocyte differentiation are known as the following hepatocyte nuclear factors (HNFs): $3 \alpha, \beta ; 4 \alpha ; 1 \alpha, \beta ; 6$ [10-14].

Controlling all these factors can lead to the better targeting of stem cell differentiation.

Li et al. argued that a three-dimensional structure of collagen-modified poly(lactic-co-glycolic acid) (PLGA) favoured growth and the differentiation of BMSCs towards hepatocyte [15]. 


\subsection{METHODS TO OBTAIN AN ORGAN MATRIX}

The organ scaffold has a number of roles; it provides a supporting structure, configures the organ in space, guides cell proliferation and differentiation, maintains cells phenotype and apoptosis by facilitating, sensing and responding to the external environment, and maintains optimal distances between cells to allow the diffusion of nutrients and oxygen [16].

Both biological and synthetic matrices have been tested for tissue regeneration.

The support matrix is intended to provide organ-specific elastic-mechanical characteristics, develop vasculature necessary to sustain tissue energy, develop the biliary tract, and provide the specific configuration of the tissue and organ.

The matrix used should be biocompatible and, for synthetic matrices, should be biodegradable with no release of toxic elements into the body.

If a resorbable (biodegradable) polymer matrix is used, it will be degraded over time and replaced with autologous tissue, reducing the foreign body inflammatory reaction [17].

A number of features of the matrix influence the characteristics of the organ: the macroscopic structure - including its appearance and surface coating, method of attachment, inflow and outflow regions of blood and bile, and vascular branching inside the organ; and the microscopic structure - where intercellular distances are evaluated, cell growth support, and the diffusion possibility of nutrients and oxygen.

Natural matrices may be formed from collagen, gelatine, matrigel, and fibronectin, and are suitable for cell growth characteristics, but have poor mechanical properties and are difficult to handle. In addition, a change of the properties of these matrices is difficult and depends on the tissue of origin [18-21].

Natural matrixes were obtained by decellularisation of the organs, maintaining functional molecules and their original, three-dimensional structure, thus being ideal as a scaffold for reconstructing new organs (Figure 3) [22,23]. Decellularisation may be accomplished by physical (agitation, freezing, thawing, pressure, mechanical massage, sonication) or chemical methods (ionic detergent, nonionic, zwitterionic, acidic or alkaline treatments, chelating agents, and hypertonic and hypotonic treatments). For this purpose, an enzyme treatment can also be used (trypsin, endonuclease or exonuclease) [23]. Often, these methods are combined in successive sequences. 


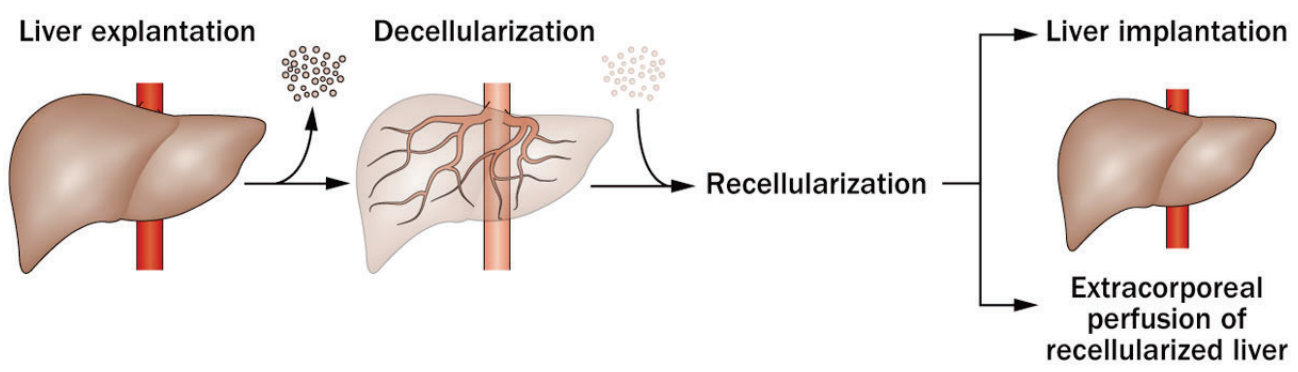

Figure 3. Decellulariaation and recellularisation of the explanted liver (from Struecker et al. 2014) [24]
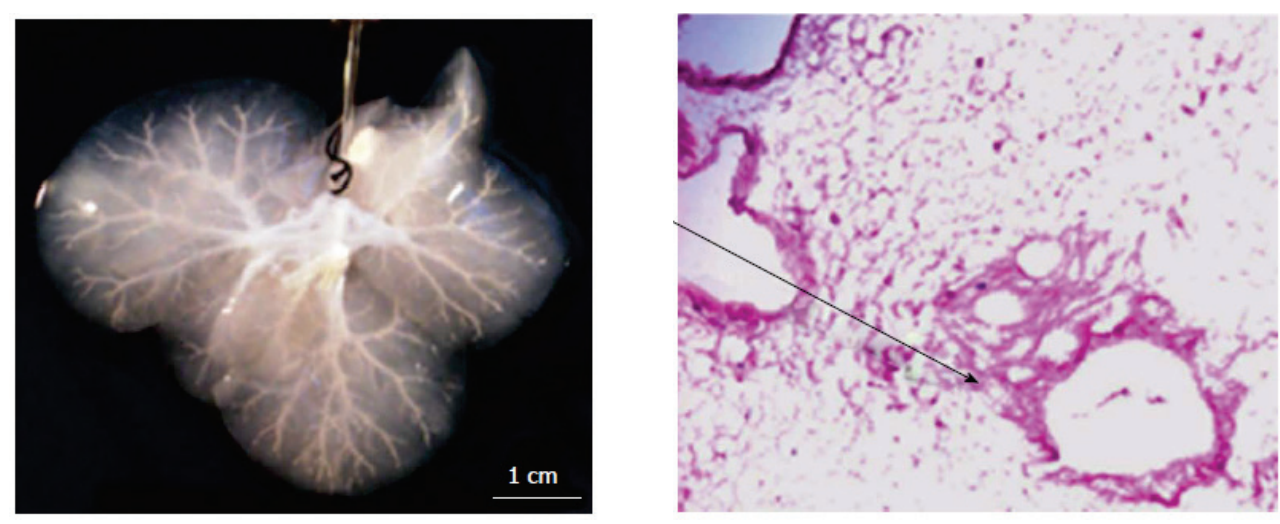

Figure 4. Ferret decellularised liver (from Booth et al. 2012) [25]

Some authors use scaffold obtained from animal organs (Figure 4); however, with this method, care must be taken to eliminate all immunological stimuli from the scaffolds [26-31].

Synthetic matrices may have varying physical and mechanical properties according to the initial design, including the microscopic and macroscopic structure, which can be configured as needed. In addition, the rate of degradation of synthetic supporting structures can be adjusted as required by changing the polymer composition used [5]. However, at present, it is difficult to simulate perfectly the Nature, with blood vessels, bile ducts, extracellular spaces, etc.

There are also fluid matrixes that encapsulate cells and suspend them in the liquid medium (living scaffolds).

Various kinds of materials have been used, such as polyesters, hydrogels, synthetic polypeptides, etc.: poly(lactic acid) (PLA); poly(glicolic acid) (PGA); PLGA; polycaprolactone (PCL). 
The disadvantages of using these polymers include a lack of stimulation of cell proliferation due to their hydrophobic nature and a lack of recognition of cellular signals [5]. In order to overcome these drawbacks, bioactive molecules are attached to the surface of inert polymers [32,33].

To create a similar structure of the ECM, nanostructured fibres created by electrospinning were used [34]. Kazemnejad et al. (2007) created a matrix of poly( $\varepsilon$-caprolactone), collagen and poly(ether sulphone) via electrospinning [34].

A synthetic scaffold can be used either to be seeded with cells or to provide support for tissue regeneration. The first attempts to generate a scaffold has a limited ability to control the microscopic structure. Various physico-chemical techniques can be used: photolithography, two-photon polymerisation, chemical vapour deposition, foaming, membrane lamination, electrospinning, etc. These techniques do not allow to control of porosity and intercommunication between networks of ducts and have no reproducible structure. These drawbacks can be overcome by rapid prototyping 3D printing techniques or fused deposition modelling (FDM).

Singare et al. described a method of achieving a basic three-dimensional structure of the liver by computer design in computer-aided design (CAD) and generation by 3D printing using a PolyJet 3D printer. The material used for the mould was poly(dimethyl-siloxane) (PDMS), which was later used for structure creation from biodegradable material [35].

Feng et al. developed a galactosylated chitosan (GC) nanofibers scaffold for enhanced properties of 3D hepatocytes growing [36].

\subsection{METHODS FOR RECELLULARISING THE SCAFFOLDS}

In order to populate the scaffold with cultured cells, various techniques are used. In most cases, the simple immersion in cell suspension is not enough. Populating the scaffold is done predominantly on the surface, which creates uneven results. A colloidal solution containing the cells is injected into the scaffold to populate it. Some authors use an intermittent vacuum in order to aspirate the suspension into the scaffold pores [15].

To further grow and differentiate these cells in a three-dimensional environment, specific growth factors should be administered. Hydrogels or slow release microspheres containing these growth factors can be used. The delivery systems can be filled with genes or peptides that accelerate cell proliferation. Using a protein-composed scaffold is useful because of cell recognition sites localised on protein surfaces that form the matrix [37-40].

It has been shown that the interaction between cells and the scaffold plays an important role in further differentiating the cells. In this interaction, the matrix 
topography and surface radicals (or recognition sites) are essential. To modulate this interaction, one can include growth factors and chemical radicals in the matrix, which may favour cell immobilisation (e.g., arginine-glycine-aspartic acid) [41].

Okano et al. described another way to obtain an artificial liver, which involved overlapping sheets impregnated with hepatocytes [42].

\subsection{APPLICATIONS OF RECONSTRUCTED ORGANS}

Multiple techniques for scaffold synthesis and cell culture possibilities from various sources show that this research is still in the initial phase. However, to achieve a functional organ, multiple tissues with complex structures and functionalities must be combined, which will require additional research from experts in bioengineering.

A functional liver must include, besides liver tissue, blood vessels and bile ducts, all integrated into a complex matrix that allows the diffusion of oxygen and nutrients, and the degradation of products to cells that populate the matrix, all which must be biocompatible with the patient immunologic self.

Production of engineered organs will allow the treatment of a number of additional patients with acute or chronic liver failure and, thus, will reduce waiting lists, which presently span 2-3 years. In addition, immunological compatibility will avoid immunosuppression, which has a number of side effects on the body, including infections and malignancies.

\subsection{CONCLUSIONS}

Regenerative medicine has enormous potential in the creation of artificial organs, which will have a particularly important impact in reducing morbidity and mortality from acute or chronic diseases.

Particularly, the mass production of liver-engineered tissues will allow a large number of patients in the end-stage of diseases or with acute liver failure to be treated, thus reducing mortality and morbidity while on the waiting list for liver transplantation.

The impediments described in this chapter are increasingly overcome by further research, allowing for a prediction that, in 10 years, such a therapy will be the standard. 


\section{REFERENCES}

1. L.V. di Bonzo, I. Ferrero, C. Cravanzola, K. Mareschi, D. Rustichell, E. Novo, F. Sanavio, S. Cannito, E. Zamara, M. Bertero, A. Davit, S. Francica, F. Novelli, S. Colombatto, F. Fagioli, M. Parola. Gut. 57(2) (2008) 223-231.

2. K.D. Lee, T.K. Kuo, J. Whang-Peng, Y.F. Chung, C.T. Lin, S.H. Chou, J.R. Chen, Y.P. Chen, O.K. Lee. Hepatology 40(6) (2004) 1275-1284.

3. S. Snykers, T. Vanhaecke, A. De Becker, P. Papeleu, M. Vinken, I. Van Riet, V. Rogiers. BMC Dev. Biol. 7 (2007) 24.

4. R. Tiruvannamalai-Annamalai, D.R. Armant, H.W. Matthew. PLoS One 9(1) (2014) e84287.

5. S. Kazemnejad. Avicenna J. Med. Biotechnol. 1(3) (2009) 135-145.

6. T. Mitaka, T. Mizuguchi, F. Sato, C. Mochizuki, Y. Mochizuki. J. Gastroenterol. Hepatol. 13 Suppl (1998) S70-S77.

7. J.W. Allen, S.N. Bhatia. Tissue Eng. 8(5) (2002) 725-737.

8. S.L. Nyberg, R.P. Remmel, H.J. Mann, M.V. Peshwa, W.S. Hu, F.B. Cerra. Ann. Surg. 220(1) (1994) 59-67.

9. E. Török, J.M. Pollok, P.X. Ma, P.M. Kaufmann, M. Dandri, J. Petersen, M.R. Burda, D. Kluth, F. Perner, X. Rogiers. Cells Tissues Organs 169(1) (2001) 34-41.

10. S. Snykers, J. De Kock, V. Rogiers, T. Vanhaecke. Stem Cells 27(3) (2009) 577-605.

11. D.A. Shafritz, M. Oertel, A. Menthena, D. Nierhoff, M.D. Dabeva. Hepatology 43(2 Suppl 1) (2006) S89-S98.

12. T. Kinoshita, A. Miyajima. Biochim. Biophys. Acta 1592(3) (2002) 303-312.

13. F. Clotman, F.P. Lemaigre. Cell Cycle 5(2) (2006) 168-171.

14. F. Lemaigre, K.S. Zaret. Curr. Opin. Genet. Dev. 14(5) (2004) 582-590.

15. J. Li, R. Tao, W. Wu, H. Cao, J. Xin, J. Li, J. Guo, L. Jiang, C. Gao, A.A. Demetriou, D.L. Farkas, L. Li. Stem Cells Dev. 19(9) (2010) 1427-1436.

16. H. Tabesh, G. Amoabediny, N.S. Nik, M. Heydari, M. Yosefifard, S.O. Siadat, K. Mottaghy. Neurochem. Int. 54(2) (2009) 73-83.

17. J.P. Vacanti, R. Langer, J. Upton, J.J. Marler. Adv. Drug Deliv. Rev. 33(1-2) (1998) 165-182.

18. S.Y. Ong, H. Dai, K.W. Leong. Biomaterials 27(22) (2006) 4087-4097.

19. R.E. Schwartz, M. Reyes, L. Koodie, Y. Jiang, M. Blackstad, T. Lund, T. Lenvik, S. Johnson, W.S. Hu, C.M. Verfaillie. J. Clin. Invest. 109(10) (2002) 1291-1302.

20. H.C. Fiegel M.D., M.V. Lioznov, L. Cortes-Dericks, C. Lange, D. Kluth, B. Fehse, A.R. Zander. Stem Cells 21(1) (2003) 98-104.

21. H. Baharvand, S.M. Hashemi, S. Kazemi Ashtiani, A. Farrokhi. Int. J. Dev. Biol. 50(7) (2006) 645-652.

22. S.F. Badylak. Transpl. Immunol. 12(3-4) (2004) 367-377.

23. T.W. Gilbert, T.L. Sellaro, S.F. Badylak. Biomaterials 27(19) (2006) 3675-3683.

24. B. Struecker, N. Raschzok, I.M. Sauer. Nat. Rev. Gastroenterol. Hepatol. 11(3) (2014) 166-176.

25. C. Booth, T. Soker, P. Baptista, C.L. Ross, S. Soker, U. Farooq, R.J. Stratta, G. Orlando. World J. Gastroenterol. 18(47) (2012) 6926-6934.

26. O. Barakat, S. Abbasi, G. Rodriguez, J. Rios, R.P. Wood, C. Ozaki, L.S. Holley, P.K. Gauthier. J. Surg. Res. 173(1) (2012) e11-e25. 
27. B.E. Uygun, A. Soto-Gutierrez, H. Yagi, M.-L. Izamis, M.A. Guzzardi, C. Shulman. Nat. Med. 16(7) (2010) 814-820.

28. P.M. Baptista, M.M. Siddiqui, G. Lozier, S.R. Rodriguez, A. Atala, S. Soker. Hepatology 53(2) (2011) 604-617.

29. K. Schenke-Layland, R.M. Nerem. Adv. Drug Deliv. Rev. 63(4-5) (2011) 195-196.

30. T. Shupe, M. Williams, A. Brown, B. Willenberg, B.E. Petersen. Organogenesis 6(2) (2010) 134-136.

31. A. Soto-Gutierrez, L. Zhang, C. Medberry, K. Fukumitsu, D. Faulk, H. Jiang, J. Reing, R. Gramignoli, J. Komori, M. Ross, M. Nagaya, E. Lagasse, D. Stolz, S.C. Strom, I.J. Fox, S.F. Badylak. Tissue Eng. Part C Methods 17(6) (2011) 677-686.

32. Y.Z. Zhang, J. Venugopal, Z.M. Huang, C.T. Lim, S. Ramakrishna. Biomacromolecules 6(5) (2005) 2583-2589.

33. J. Venugopal, Y.Z. Zhang, S. Ramakrishna. Nanotechnology 16(10) (2005) 2138-2142.

34. S. Kazemnejad, A. Allameh, M. Soleimani, A. Gharehbaghian, Y. Mohammadi, N. Amirizadeh, N. Kaviani. Iran. J. Biotechnol. 5(4) (2007) 201-211.

35. S. Singare, S.Y. Zhong, Z.Z. Sun. J. Biomim. Biomat. Tissue Eng. 11 (2011) 73-80.

36. Z.Q. Feng, X. Chu, N.P. Huang, T. Wang, Y. Wang, X. Shi, Y. Ding, Z.Z. Gu. Biomaterials 30(14) (2009) 2753-2763.

37. M.E. Davis, P.C. Hsieh, T. Takahashi, Q. Song, S. Zhang, R.D. Kamm, A.J. Grodzinsky, P. Anversa, R.T. Lee. Proc. Natl. Acad. Sci. U.S.A. 103(21) (2006) 8155-8160.

38. O. Oliviero, M. Ventre, P.A. Netti. Acta Biomater. 8(9) (2012) 3294-3301.

39. S. Zhang, G. Wang, X. Lin, M. Chatzinikolaidou, H.P. Jennissen, M. Laub, H. Uludağ. Biotechnol. Prog. 24(4) (2008) 945-956.

40. M. Nune, P. Kumaraswamy, U.M. Krishnan, S. Sethuraman. Curr. Protein Pept. Sci. 14(1) (2013) 70-84.

41. M. Lutolf, J. Hubbell. Nat. Biotechnol. 23(1) (2005) 47-55.

42. J. Yang, M. Yamato, T. Shimizu, H. Sekine, K. Ohashi, M. Kanzaki, T. Ohki, K. Nishida, T. Okano. Biomaterials 28(34) (2007) 5033-5043. 